$$
\begin{aligned}
& \text { I.N.R.A. } \\
& \text { BIBLIOTHEQUE UO } 35906 \\
& \text { DOMAINE OE CROUELLE } \\
& \text { CLERMONT-Fo CO CEOEX? } \\
& \text { 7IZICS }
\end{aligned}
$$

\title{
REPERCUSSIONS DES AVITAMINOSES \\ SUR LE DEVELOPPEMENT EMBRYONNAIRE \\ CHEZ LE MAMMIFÈRE ET L'OISEAU
}

PAR

\section{Jean ADRIAN}

Laboratoire de Biochimie de la nutrition du C. N. R. S., Bellevue, S. et O.

\section{PLAN DU MÉMOIRE}

\section{Introduction.}

Avitaminoses maternelles et développement embryonnaire chez le Mammifère.

Avitaminoses maternelles et développement embryonnaire chez la Poule.

Localisation des mortalités embryonnaires au cours des avitaminoses de la Poule.

Bibliographie.

\section{INTRODUCTION}

Un adage prétend que la Poule pond par le bec, soulignant ainsi l'importance de l'alimentation pour la ponte. Mais cette influence se poursuit au-delà, car on a observé maintes fois que la ration de la mère conditionnait l'éclosion des œufs.

Ceci est particulièrement vrai en ce qui concerne les vitamines: une ration carencée entraîne inévitablement une diminution puis un arrêt de l'éclosion, avant de provoquer la cessation de la ponte elle-même. JACQUOT et ADRIAN (34) ont récemment attiré l'attention sur ce fait.

Ce phénomène s'explique chez 1'oiseau par le fait que l'incubation ne permet pas la synthèse des vitamines, à l'exception de la niacine. Il convient donc que l'œuf, au moment de la ponte, contienne les quantités de vitamines nécessaires à l'embryon, sinon le développement de ce dernier risquera de demeurer incomplet.

Bien que les faits soient moins nets, il en est de même chez les mammifères pour lesquels un certain quantum vitaminique est indispensable à l'évolution normale de la gestation. Il existe une bibliographie relativement abondante concernant l'influence des avitaminoses sur la repro- 
duction des animaux de laboratoire (Rat) ou de ferme (Porc, ovins et bovins). Ces travaux (Giroud, JACQUO'T, WARKANY) font état de troubles multiples qui vont de l'avortement pur et simple aux malformations embryonnaires.

Par contre, les données sont plus rares en ce qui concerne les oiseaux et notamment la volaille ; c'est pourquoi nous donnerons plus d'importance à l'étude de l'oiseau qu'à celle du mammifère, estimant que la liste des anomalies et la courbe de mortalité des embryons de Poules carencées en vitamines contribueront à une meilleure connaissance des phénomènes de reproduction chez une espèce considérée longtemps comme secondaire et devenue depuis peu d'une importance économique primordiale.

En bref, pour situer le problème dans son ensemble, nous rappellerons tout d'abord les manifestations des avitaminoses au cours du développement embryonnaire du mammifère avant d'envisager le cas de l'oiseau.

\section{I. - AVITAMINOSES MATERNELLES ET DÉVELOPPEMENT EMBRYONNAIRE CHEZ LE MAMMIFÉRE}

Tous les facteurs vitaminiques n'ont pas été étudiés également du point de vue qui nous intéresse : c'est ainsi que l'on connaît mal les répercussions sur l'embryon d'une athiaminose, alors que, par contre, la description d'un embryon subissant une carence en vitamine A est faite d'une manière détaillée.

Par ailleurs, il convient d'avoir à l'esprit quelques observations d'ordre général.

I. - Etant donnée l'activité de la microflore du rumen, les polygastriques sont insensibles aux avitaminoses B.

2. - Certaines avitaminoses requièrent des artifices particuliers; de ce fait on connaît mal l'influence de la niacine ou de la biotine sur le développement embryonnaire.

3. - Toute avitaminose aiguë entraîne la stérilité, soit par défaut de fécondation, soit par résorption des fœtus.

L'action tératogénique des avitaminoses s'excerce dans une zone étroite correspondant à une chute de $30 \mathrm{p}$. Ioo des réserves hépatiques de la mère (Giroud, 24).

4. - L'action des vitamines au cours de la gestation obéit au facteur chronologique : une carence établie avant ou au moment de l'accouplement produit des accidents et des troubles embryonnaires, alors que la même carence sera sans influence si elle est instaurée dans la seconde partie de la gestation (JAcQUOT).

En résumé, si l'on veut obtenir une avitaminose possédant un pouvoir tératogène, il est nécessaire de réunir les 2 conditions suivantes : 
- la mère doit être carencée dès l'accouplement ;

- la déficience doit être relativement modérée.

La vitamine A. - La répercussion la plus caractéristique de cette carence est la mise bas d'animaux aveugles. Cette cécité a été l'objet de nombreuses études et son étiologie est maintenant élucidée. Deux causes peuvent la provoquer :

- soit que la déficience en vitamine A entraîne un épaississement de la boîte crânienne ayant pour conséquence une compression du chiosma optique et une cécité concomitante (Moore, Huffman et Duncan, 45),

- soit que la différenciation de l'ceil demeure incomplète: la chambre antérieure, l'iris et les corps ciliaires sont absents, le corps vitreux est remplacé par du tissu conjonctif ; la rétine elle-même se présente sous forme de cortex cérébral et on y observe des colobomes. Ces images traduisent l'absence de différenciation dans les premiers stades du développement embryonnaire (WARkANy et SCHRAFFENBERGER, 59). Ces malfomations oculaires sont visibles chez le Rat dès le I $^{\text {e }}$ jour de la gestation.

En dehors de ces troubles, l'avitaminose A produit chez le jeune Rat issu de mère carencée un retard de dentition affectant spécialement les incisives et les molaires (Mel,anBy, 44).

De même, Wilson et Warkany (6o) constatent chez les embryons de Rat des reins en "fer à cheval ", c'est-à-dire joints sur la ligne médiane, des malformations nombreuses de l'appareil génito-urinaire portant surtout sur le sexe mâle (les testicules restent remontés, la gouttière uréthale demeure ouverte).

Hale $(25,26)$ précise les répercussions d'une avitaminose A chez l'embryon de la Truie : les symptômes les plus importants sont ceux qui se rapportent à l'appareil oculaire et qui provoquent une microphtalmie ou même une anaphtalmie. En plus, les embryons portent des fentes palatales avec malformations de la partie antérieure du museau (bec de lièvre) ainsi que des anomalies auriculaires.

Enfin, comme nous l'avons souligné, à des degrés plus graves de carence, les avitaminoses provoquent une stérilité des femelles. Ce fait s'observe notamment dans les avitaminoses $\mathrm{A}$ où l'on obtient fréquemment la mise bas d'animaux morts nés ou non-viables, ou bien encore des résorptions de fotus. Bien que ceci dépasse le cadre de notre propos il était utile de signaler la fréquence de ce phénomène, observée aussi bien sur mouton (HAR'T et coll., 28), que chez le Porc (Hughes, 3I) ou le Rat (MASON, 42).

La vitamine $\mathbf{D}$. - I a déficience des mères en ce facteur entraîne l'apparition du rachitisme chez les embryons. Ce trouble est suffisamment connu pour que nous soyons dispensé de le décrire minutieusement. Signalons seulement les conclusions d'un travail de WARkaNy (55) qui 
observe chez l'embryon de Rat une courbure accentuée des os longs comme le radius et le cubitus, le tibia et le péroné, ainsi que l'aspect anguleux des côtes.

La nature elle-même de l'os est atteinte, la zone cartilagineuse étant plus étendue et la limite de l'ossification irrégulière; néanmoins, les os touchés ne présentent pas les caractéristiques exactes des tissus osseux rachitiques de 1'adulte.

La vitamine B2. - Bologna et coll. (5), Giroud et coll. (2I) et WARKANY et coll. (56) décrivent les malformations subies par l'embryon de Rat à la suite d'ariboflavinose maternelle ; ces troubles sont multiples. Le squelette est atteint: on constate un raccourcissement de certains os et notamment de la mâchoire inférieure, du radius et cubitus, du tibia et du péroné. Parfois on note même l'absence d'un de ces os. On relève, par ailleurs, du syndactylisme, des fentes du palais dans l'axe longitudinal.

L'étude histologique des os montre une altération des parties cartilagineuses et du tissu osseux lui-même. I a brachymélie touche principalement les segments distaux. Il apparaît aussi que les parties cartilagineuses sont responsables du syndactylisme.

WARKANY et coll. (57) ont montré que ces malformations survenaient le $\mathrm{I} 3^{\mathrm{e}} \mathrm{I} 4^{\mathrm{e}}$ jour de la gestation; les cartilages étant atteints au moment de la chondrification (58). C'est à ce stade que la déficience en riboflavine est critique, puisqu'une administration de vitamine $\mathrm{B} 2$ peut encore empêcher l'apparition de symptômes (57).

L'acide pantothénique. - Les répercussions de la carence en ce facteur ont été particulièrement étudiées par LEFEBVREs $(23,39)$ qui a noté 2 anomalies principales chez le Rat : l'exencéphalie et l'anophtalmie.

Le premier de ces symptômes se traduit par l'absence de la voûte crânienne: le cerveau est en contact direct avec l'épiderme. L,e tissu cervical est altéré et il existe alors une sorte d'anencéphalie. Par ailleurs, l'œil est plus ou moins atteint : tantôt il subsiste une ébauche de très petite taille et de constitution anarchique, tantôt l'œil est totalement absent; cependant, même dans ce cas, on trouve les annexes de l'appareil oculaire (paupières, glandes lacrymales).

D'autres symptômes secondaires peuvent se rencontrer, tels des œdèmes, des hémorragies aux extrémités des membres, qui provoquent à leur tour des déformations du squelette des doigts.

L'acide folique. - THIERsch et coll. (53), en ajoutant à un régime un antagoniste de l'acide folique, arrivent à obtenir des embryons non viables et présentant une altération du mésenchyme.

HoGas et coll. (29) ont mis en évidence qu'une carence en acide folique des mères entraînait 1'apparition de petits hydrocéphales; ce 
résultat étant obtenu aussi bien par régime carencé que par adjonction d'anti-acide ptéroylglutamique.

Reprenant cette étude, Giroud et LefFevbres (22) notent par ordre d'importance: des troubles oculaires, des malformations du museau et des anomalies du tronc.

L'œil se développe d'une manière anarchique, et ses différentés parties apparaissent très plissées; la fente choroïdienne demeure ouverte. Le cristallin existe, mais très déformé. On relève, par ailleurs, des becs de lièvre et une atrophie des fosses nasales.

Enfin, les organes du tronc (cœur, foie, intestin) se trouvent souvent déplacés par suite d'un manque de fermeture de la paroi du corps. Ce symptôme semble caractéristique de la carence folique, nous le retrouverons chez la Volaille.

Ces anomalies ne sont cependant pas les seules observables dans les embryons déficients en acide folique. Dans la deuxième moitié de la gestation de la Rate, si la ration renferme un anti-acide folique les embryons offrent les symptômes de l'anémie, un retard de développement de certains organes et des anomalies touchant le squelette (fente du palais, syndactylisme) (NELson et coll., I952).

Discussion. - Les organes de l'embryon de mammifère particulièrement sensibles aux carences vitaminiques sont l'œil d'une part, le squelette d'autre part.

I1 est assez difficile de rattacher cette localisation aux signes cliniques classiques que déterminent les avitaminoses chez les animaux à l'état adulte. Chez ces derniers chaque avitaminose a sa manifestation propre; il n'en est pas de même à l'endroit de l'embryon. C'est ainsi que le bec de lièvre et le syndactylisme sont la conséquence aussi bien de l'avitaminose A que des carences en riboflavine ou en acide folique.

Par ailleurs, la manifestation des avitaminoses maternelles sur l'embryon n'a pas un caractère univoque et spécifique. Il s'agit le plus souvent de réponse "en éventail", qui peut atteindre tantôt l'une, tantôt l'autre des ébauches de l'embryon.

C'est pourquoi les manifestations des avitaminoses varient selon 'optique de 1'auteur qui les étudie. Par exemple, lors de la carence en acide folique Giroud s'est préoccupé principalement des lésions anatomiques alors que NELSON envisage les troubles de l'hématopoièse.

Nous nous bornerons à ce court tableau de la sensibilité embryonnaire aux avitaminoses maternelles des mammifères avant d'examiner plus longuement ce qui se passe dans le cas de l'embryon de Poule. 


\section{II. - AVITAMINOSES MATERNELLES ET DÉVELOPPEMENT EMBRYONNAIRE CHEZ LA POULE}

Les déficiences vitaminiques chez l'embryon de Poule peuvent être obtenues par carence directe de la Poule elle-même, qui, ainsi ne transmet à 1'œuf que des quantités sous-optimales de vitamines, insuffisantes pour un développement et une éclosabilité normales. On peut arriver au même résultat par une voie détournée en injectant dans l'œuf des antivitamines.

Comme nous l'avons déjà dit, les avitaminoses se traduisent essentiellement par une diminution de la ponte et une chute du taux d'éclosion. Ces faits sont trop connus pour qu'on doive les rappeler. Nous nous limiterons donc à l'aspect plus particulier qui se rapporte aux troubles du développement embryonnaire, soit de l'embryon, soit du poussin au moment de 1'éclosion.

La vitamine $\mathbf{A}$. - Un seul travail concerne directement l'influence de la carence en vitamine A sur l'embryon de poule. Il s'agit des observations de PolK et Sire (48) sur les malpositions de l'embryon. Ces auteurs relèvent les positions anormales de l'embryon dans 2 lots d'œufs ; le premier provenant de poules alimentées normalement et le second de pondeuses déficientes en vitamine $A$. Les 2 lots étaient respectivement de 3 I 56 et de 2 34I oufs.

Voici les pourcentages de chacune des malpositions observées:

\begin{tabular}{|c|c|c|}
\hline Description de la malposition & (Eufs normaux & (Eufs déficients \\
\hline . tête entre les pattes & $\mathbf{I}, \mathrm{O}$ & $\mathrm{I}, 7$ \\
\hline 2. tête dans la petite extrémité de l'ceuf & 0,35 & 0,60 \\
\hline bec sous l'aile gauche $\ldots \ldots \ldots \ldots \ldots$. & 0,8 & $\mathrm{I}, 30$ \\
\hline tête éloignée de la poche d'air....... & 0,0 & 0,02 \\
\hline pieds au-dessus de la tête............ & 0,0 & 0,0 \\
\hline 6. bec au-dessus de l'aile droite & $\mathrm{I}, 35$ & 2,45 \\
\hline
\end{tabular}
droite.

Rappelons que la position normale veut que le bec soit sous l'aile

Il ressort de ces quelques chiffres que la vitamine $\mathrm{A}$ double à peu près la fréquence des malpositions. Ceci aura des répercussions au moment de l'éclosion, car il est évident que certaines des positions notées sont incompatibles avec la possibilité pour le poussin de déchirer la coquille au $2 \mathrm{I}^{\mathrm{e}}$ jour de l'incubation.

D'autres travaux portent non sur l'embryon lui-même, mais sur le jeune poussin carencé en vitamine $\mathrm{A}$; nous les citons à titre de complément d'informations et pour faire ressortir la similitude des symptômes de carence entre la volaille et les autres espèces animales.

C'est ainsi que Chapman (6) relève les troubles suivants chez des poussins de 4 semaines:

- sécrétion lacrymale excessive ;

- faiblesse grave des pattes ; 
- retard de croissance ;

- calculs rénaux et urinaires ;

- kératinisation des épithéliums du bec et de l'œsophage.

Matzko et coll. (43) confirment l'existence de ces symptômes et ajoutent :

- une résistance aux infections amoindries;

- une conjonctivite et d'autres troubles oculaires;

- des lésions buccales, rénales, pulmonaires, nasales, etc.

Enfin, on peut citer les conclusions de Feld et Mellamby (I5), démontrant que des greffes d'ectoderme d'embryon de Poule transposées sur un milieu hypervitaminé ( $\mathrm{I}$ o0o à $3000 \mathrm{U} \mathrm{I} / \mathrm{IOO} \mathrm{cc}$ ) fabriquent un épithélium sécréteur du mucus, à la manière de la muqueuse nasale, et ne peuvent plus former de cellules kératinisées. Ce phénomène est réversible en ce sens que si la greffe passe du milieu enrichi à un milieu normal ( 250 à $300 \mathrm{U} \mathrm{I/I00} \mathrm{cc)} \mathrm{il} \mathrm{se} \mathrm{forme} \mathrm{un} \mathrm{épithélium} \mathrm{squameux} \mathrm{et} \mathrm{kéra-}$ tinisé sous le tissu producteur du mucus, qui a lui-même tendance à disparaitre.

La vitamine E. - Les répercussions sur l'embryon de Poule d'une déficience en vitamine $\mathrm{E}$ ont été analysées par Adaustone $(\mathrm{I}, 2)$ d'une part, et par F'ERGuson et coll. (I6) d'autre part.

Le premier a révélé l'existence d'un état hémorragique particulier au $4^{\mathrm{e}}$ jour. Il observe principalement des hémorragies, à l'extérieur comme à l'intérieur, du colome, une désintégration des vaisseaux sanguins $\mathrm{du}$ blastoderme.

En même temps, c'est-à-dire toujours vers le $4^{\mathrm{e}}$ jour, il peut se former dans le blastoderme une sorte d'anneau qui interrompt ou inhibe la circulation vitelline et provoque aussi la mort de l'embryon.

Si ce stade $\mathrm{du} 4^{\mathrm{e}}$ jour est passé, d'autres risques apparaissent et notamment des ruptures spontanées de canaux vasculaires, avec une particularité qui semble propre à la carence en vitamine $\mathrm{E}$ : à l'endroit de l'hémorragie on reconnaît une agrégation de cellules d'un type particulier: le noyau est uniformément sombre (pycnose) et le cytoplasme demeure clair.

FERGUSON, de son côté, s'est préoccupé des malformations oculaires de l'embryon de Dindon; elles sont nombreuses et entraînent nécessairement la cécité des animaux survivants.

On rencontre tout d'abord un renflement de la cornée, qui peut aller jusqu'à faire croire à une saillie de l'œil dans les cas extrêmes. Associé à ce phénomène, on note une forme irrégulière de l'iris. Parfois les vaisseaux sanguins de la conjonctive sont dilatés et on peut déceler des œè̀mes aux paupières.

A l'intérieur de l'œil les perturbations sont multiples: l'humeur vitreuse est souvent hémorragique. La lentille est particulièrement tou- 
chée : on constate une dégénérescence de sa partie centrale et postéricure ; en la disséquant on détache une seconde lentille minuscule et de plus il s'écoule un liquide aqueux.

Enfin, dans les derniers stades du développement, il se dépose un louche jaune-verdâtre entre la cornée et la lentille.

Si les œufs proviennent d'une ration équilibrée en vitamine $\mathrm{E}$, aucun de ces troubles n'apparaît. Les yeux sont normaux : la pupille est ronde, 1'humeur vitreuse claire, la lentille est cristalline et solide.

En ce qui concerne les embryons carencés, on peut noter (r6) une réduction de la longueur du corps, des pattes et des ailes. Au moment de l'éclosion, les poussins piquent la coquille, mais ne peuvent cependant pas éclore.

Parmi 7I embryons morts pendant les quelques jours qui précèdent 1'éclosion, FERGUSON relève les pourcentages suivants de malformations :

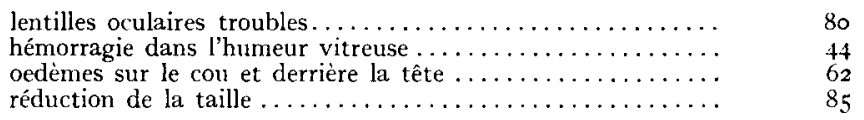

La vitamine B1. - NABER et coll. (46) ont inhibé le développement normal de l'embryon en injectant dans l'œuf des anti-thiamines (néopyrithiamine ou oxythiamine). Ces injections sont particulièrement efficaces si elles sont pratiquées au début de l'incubation.

L'oxythiamine provoque des cedèmes sur les régions proches $\mathrm{du}$ point d'injection, et une accumulation d'acide pyrivique; par contre, cette antivitamine ne déclenche pas de troubles neurologiques.

En présence de néopyrithiamine, au contraire, l'embryon développe les symptômes nerveux classiques de la polynévrite.

Si l'injection a lieu dans la seconde moitié de l'incubation, l'embryon arrive au terme de son développement, mais le poussin présente de la polynévrite : ataxie, rétraction de la tête, perte d'équilibre et paralysie.

Dans les embryons morts avant l'éclosion, on relève des cedèmes, des hernies abdominales et des hémorragies en grande abondance.

Nous n'avons pas d'exemples des effets d'une carence directe en thiamine chez l'embryon de Poule, mais ceci semble maintenant superflu, en ce sens que la description des signes cliniques obtenus par injection d'antithiamines correspond au tableau classique de la déficience en vitamine BI. Il peut être curieux de noter que les 2 antivitamines semblent se partager la production des signes d'avitaminose, l'une touchant le tissu nerveux tandis que l'autre provoque les autres troubles (œedèmes, etc.) de la carence.

La vitamine B2. - L'effet de la carence en riboflavine sur l'embryon de Poule a été observé à 2 reprises.

ENGEL et coll. (I4), en I940, ont d'abord déterminé la quantité minimum de vitamine $B 2$ compatible avec une éclosion normale : on ne 
peut descendre au-dessous de 2,5 à 3,o ug par g d'albumen. Ce chiffre correspond approximativement à une chute d'environ 20 à $30 \mathrm{p}$. 100 de la teneur normale de l'albumen en riboflavine, et confirme les résultats de LEFEBVRES (24) sur le Rat.

Dans I7 embryons déficients en vitamine B2, ENGEL et coll. observent les troubles suivants, exprimés en pourcentage:

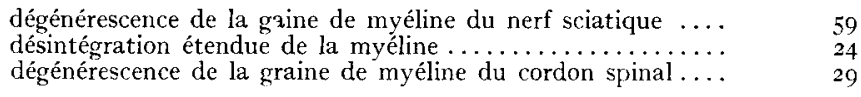

En plus de ces altérations du tissu nerveux, les auteurs relèvent une atrophie du thymus dans la moitié des embryons déficients ; par contre, le cerveau ne présente pas de lésions, et les reins semblent normaux.

ROMANOFF et BAUERNFEIND (49) montrent que la déficience en riboflavine provoque 3 pointes de mortalité pendant l'incubation (voir graphiques I et II), et observent l'état des embryons à chacune de ces périodes, c'est-à-dire les $4^{\mathrm{e}}, \mathrm{I} 4^{\mathrm{e}}$ et $2 \mathrm{I}^{\mathrm{e}}$ jour.

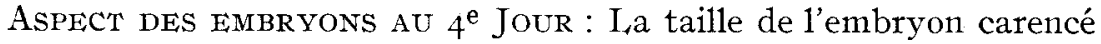
est nettement plus petite; le blastoderme révèle un début de désorganisation du système circulatoire et l'amorce d'un anneau provoquant la mort de l'embryon, ainsi qu'ENGEI l'avait noté.

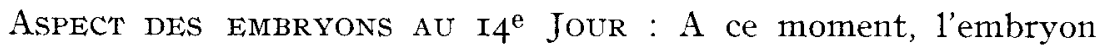
carencé pèse $6 \mathrm{~g}$ contre $9 \mathrm{~g}$ pour l'œuf normal.

$\mathrm{I}$ a déficience en vitamine $\mathrm{B} 2$ se traduit par: courts ;

- une micromélie généralisée: les membres sont extrêmement

- un prognatisme supérieur : le bec inférieur est raccourci ;

- un état œéémateux dans la région du cou;

- un retard dans le développement du duvet.

En plus, le foie présente un aspect pathologique, notamment le lobe gauche. Au lieu de jaune clair, sa couleur peut aller de brun à vert foncé, et il est coupé de bandes blanches étroites, marquant une atrophie du tissu hépatique.

ASPECT DES EMBRYONS AU $2 \mathrm{I}^{\mathrm{e}}$ JOUR : Il semble qu'à cette époque la déficience provoque 2 types d'embryons: les uns ont un retard de croissance de $40 \mathrm{p}$. Ioo par rapport aux embryons normaux, tandis que d'autres présentent une atrophie insignifiante (Io p. I00).

La carence entraîne un plumage très réduit et une déformation des pattes caractéristique de l'ariboflavinose (curled toe) : les pieds sont tournés l'un vers l'autre, et les animaux s'appuient sur leurs tarses et métatarses pour marcher.

La vitamine PP. - Ce facteur étant synthétisé au cours de l'incubation, on ne peut mesurer les effets d'une déficience en niacine chez l'embryon de Poule. Il faudrait injecter des anti-vitamines dans la 
deuxième moitié de l'incubation pour obtenir une carence artificielle en cette vitamine. Par ailleurs, Hansborough (27) a pratiqué des injections de niacine dans l'œuf, mais à des doses beaucoup trop fortes pour que les résultats obtenus puissent être pris en considération : dans les conditions de l'expérience il était inévitable de perturber l'embryon.

La vitamine B6. - Des travaux relatent l'influence néfaste d'injections d'antivitamines B6 sur l'éclosabilité des œufs ; néanmoins, le rôle de ces substances sur le développement proprement dit de l'embryon a été quelque peu négligé.

KARNOFSKy et coll. (38), en I950, ont effleuré le sujet, et concluent que la méthoxypyridoxine et la desoxypyridoxine peuvent provoquer la mort de l'embryon sans en modifier le poids, ni sans faire apparaitre des malformations anatomiques. Il faut cependant souligner que ces auteurs n'ont pas cherché principalement à découvrir d'éventuelles altérations tissulaires ou des modifications microscopiques. Ils concluent, en outre, gue le mécanisme de toxicité des anti-pyridoxines n'est pas élucidé.

L'acide folique. - Un premier travail, de WAGLEY et MORGAN (54) rapporte l'action d'un antagoniste de l'acide folique au cours du développement embryonnaire. Le $7^{\mathrm{e}}$ jour de l'incubation on pratique des injections d'acide amino-4- ptéroylglutamique, et les auteurs en observent le retentissement dans le domaine hématopoïétique. Ils constatent des modifications qualitatives et quantitatives : dans les premières se rangent des altérations du noyau des cellules hématopoiétiques : pycnose, caryolyse et caryorexie. De plus, les ilots sanguins du sac vitellin diminuent en nombre et en taille. Ennfin, à la dose de o,005 mg 1'acide amino-4ptéroylglutamique entraîne une chute du nombre des hématies ( $I, 3$ million par cc contre $\mathrm{I}, 8$ million) et de la quantité d'hémoglobine (5, I g pour roo cc contre $6,5 \mathrm{~g}$ ).

KARNOFSKy et coll. (36) ont repris cette étude en utilisant des injections d'acide amino-4- diméthyl 9-1o ptéroylglutamique ou acide amino-4-méthyl Nio ptéroylglutamique. Ireur action sur le poids des embryons est très nette :

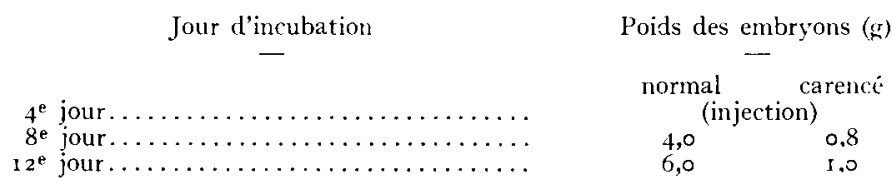

A 12 jours, les embryons offrent les anomalies snivantes:

- la tête est aplatie;

- les yeux petits, bien qu'on observe une dilatation fréquente de la chambre antérieure ;

- la partie inférieure du bec est souvent très réduite et parfois on en constate une absence totale ; 


\section{ERRATA}

Deux modifications sont à apporter au mémoire de M. MERAT intitulé : Génétique factorielle et production chez les volailles - I - Plumage "Hermine " ou "Sauvage" relation avec la croissance en poids - paru dans les Annales de Zootechnie, nº 2, 1958 :

$I^{0}$ page 138 , ligne 2 , après " ... attribuer les différences moyennes de croissance observées à l'action des allèles e ou e + , ajouter : " ou de gènes liés ».

$2^{\circ}$ page 140 , ligne 6 , au lieu de " qui assurent la croissance la plus régulière », écrire : "qui s'accompagnent de la croissance la plus régulière ». 


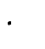


- le cou est long et tordu sur lui-même ;

- les viscères sont parfois éparses à l'extérieur de l'embryon ;

- le cour est entouré d'une poche d'eau ou de fluide ;

- les pattes sont anormales et souvent les membres postérieurs sont pratiquement absents ;

- enfin, les embryons présentent des œdèmes plus ou moins généralisés.

SUnde et coll. $(52)$ se sont penchés sur les modifications anatomiques engendrées au cours de la carence en acide folique. On note du syndactylisme, et une déformation de la partie supérieure du bec qui confère à l'animal une sorte de "bec de perroquet".

Dans le squelette, il est fréquent d'observer une courbure accentuée du tibiotarsus, mais le tarsometatarsus n'est pas atteint.

La biotine. - Cravens et coll. (ro) ont analysé les symptômes de carence en biotine chez des embryons au $8^{\mathbf{e}}$ jour de l'incubation. Par ordre d'importance ils classent d'abord la chondrodystrophie et le syndactylisme, et ensuite viennent les hémorragies, les anomalies du plumage, les odèmes et le retard de taille.

Voici les pourcentages de troubles observés au $8^{\mathrm{e}}$ jour :

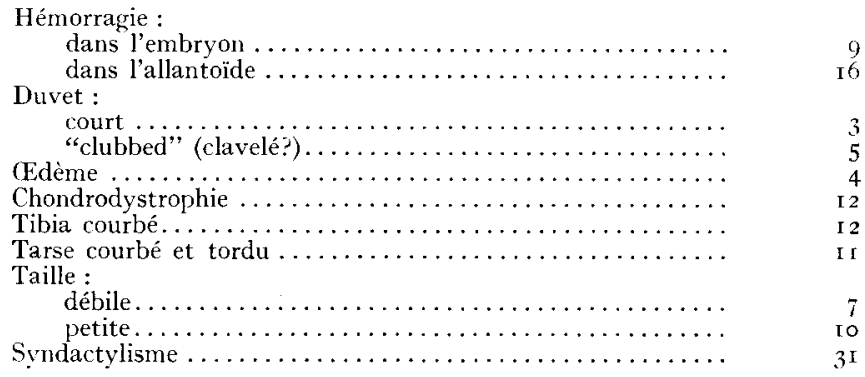

Le terme de chondrodystrophie est réservé aux embryons présentant un "bec de perroquet" accusé. Les auteurs estiment que ce symptôme est caractéristique de la carence en biotine.

Le duvet "clubbed" se rencontre principalement sur le cou et l'abdomen.

Cette étude a été reprise par Couch et coll (9) qui mettent l'accent sur les déformations osseuses des embryons:

- les os subissent, en général, un raccourcissement, comme cela se voit pour le tibiotarse, le crâne, les pattes et les ailes. De plus, les os sont souvent marqués en leur milieu par un épaississement ou un renflement, c'est le cas pour l'humérus, le radius, une partie du métacarpe, etc ;

- on observe parfois une rétraction de la tête ;

- le symptôme le plus frappant concerne les pattes: on note du pérosis en grande abondance: les articulations du jarret sont distendues et déformées ce qui se traduit par une position anormale des pattes. 
Les pattes sont raides, courbées, et tendues vers l'arrière ; en conséquence, l'animal ne peut tenir debout à l'éclosion.

La vitamine B12. - Ce facteur récent a fait l'objet de nombreux travaux, les répercussions de sa déficience dans l'œuf ont étéétudiées abondamment.

Les premières observations sont celles de OLCESE et coll. (47), qui peuvent se résumer ainsi:

- myoatrophie de la patte (longueur normale, mais minceur extrême);

- état hémorragique répandu sur tout le corps. Les hémorragies se voient dans les muscles et les parties cartilagineuses des os. Ceci es cause de la cotleur rouge sombre rencontrée dans les articulations, et principalement au joint tibiotarsal-tarsométatarsal. Ce symptôme peut être rapproché du scorbut ;

- on rencontre également des hémorragies dans 1'allantoïde ;

- enfin, les $2 / 3$ des embryons ont une position anormale : la tête entre les cuisses.

FERGUSON et Couch (I7, I8, I9) ont repris cette étude et ont confirmé les observations de OLCESE ; en plus, ils notent:

— des œdèmes à des degrés divers, et souvent généralisés ;

- un plumage déficient (ce signe est caractéristique de la carence) ;

- le cœur est pâle, dilaté, de forme irrégulière, avec des hémorragies dans 46 p. Ioo des embryons; les auricules sont engorgés de sang;

- le foie est aussi hémorragique dans $4 \mathrm{I}$ p. Ioo des cas. On y relève des infiltrations graisseuses;

- le rein est atteint dans les mêmes conditions : il est très hémorragique ;

- les parois du tube digestif sont extrêmement minces ; l'iléon est parfois dilaté et rempli d'un liquide verdâtre. Là aussi des hémorragies se produisent : dans le jabot, le gésier, le duodénum, l'iléon, et la région péritonéale ;

- 1a thyroïde est hyperplasique, et cette anomalie survient surtout à la fin de $1^{\prime}$ 'incubation ( $\mathrm{I} 7^{\mathrm{e}}$ au $2 \mathrm{I}^{\mathrm{e}}$ jour) ;

- les muscles sont plus petits et semblent " tendinous".

Toujours FERGUSON et coll. (20) analysent 139 embryons et expriment quantitativement les diverses anomalies de la carence en BI2. I,eurs résultats sont donnés en p. Ioo ci-dessous :

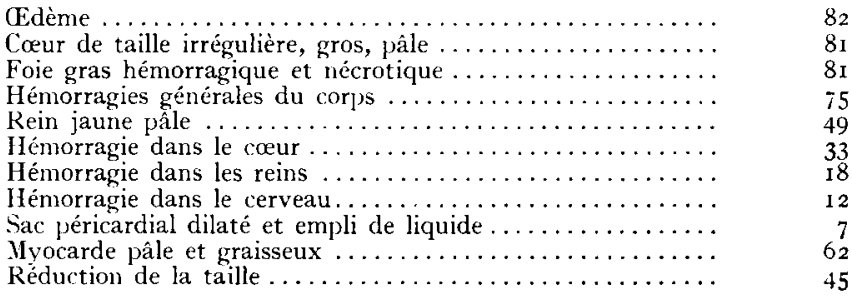


Dans cette déficience, il existe un signe qu'il est difficile de chiffrer et qui, néanmoins, offre un intérêt particulier : c'est l'état graisseux de nombreux organes de l'embryon.

Les fibres musculaires sont distendues par des œdèmes et les globules de graisse qu'on décèle sont plus gros que la normale. Néanmoins, les muscles des carencés sont plus petits que chez les embryons normaux. Le retard de croissance de 1'embryon atteint du reste près de $50 \mathrm{p}$. roo.

Contrairement à ce qu'on aurait pu attendre, le foie n'apparaît pas extrêmement gras, néanmoins les vacuoles de graisse sont plus. nombreuses. Cet organe est cependant atteint par la carence en vitamine BI2 : on note des régions hémorragiques et de larges lésions nécrotiques localisées surtout vers la tranche des lobes du foie. Ces lésions ne provoquent pas de réactions inflammatoires. Enfin, ces foies apparaissent riches en globules rouges.

On observe des gouttelettes de graisse, plus grosses que la normale, dans les tissus du tube digestif, les alvéoles pulmonaires et l'épithélium de la trachée et dans celui du rein.

Ces accumulations graisseuses du foie, des reins, du cour et du tube digestif observées au cours de la carence $\mathrm{BI} 2$ disparaissent par injection de BI2 dans l'œuf (FERGUson et Couch, I7).

Au sujet de ces infiltrations, il faut souligner que l'aspect pathologique des cellules cardiaques, rénales et hépatiques ne sont pas proportionnelles à la quantité de lipides qu'elles renferment (I8).

Enfin, dans les cas d'hémorragies cérébrales, on retrouve du sang dans les espaces subarachnidoïdiens et dans le tissu cervical. On a constaté quelques lésions dégénérescentes du cerveau et du cordon spinal, avec présence simultanée d'hématies dans ces organes.

Par ailleurs, d'autres effets de la déficience B I2 ont encore été observés.

Hsu et coll. (30) ont mesuré les quantités d'érythrocytes et d'hémoglobine dans le sang d'embryons carencés ou supplémentés par $2 \mu g$ de Br2 :

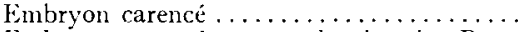

Embryon carencé $+2 \mu g$ de vitamine $\mathrm{B}_{12}$.

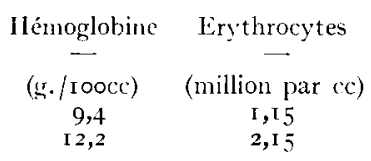

Ces taux différents sont responsables d'une production de $\mathrm{CO}_{2}$ moins élevée dans la carence en vitamine BI2, telle est la conclusion de MARIAKULANDAI et McGinnis (4I).

En résumé, la déficience en vitamine $\mathrm{BI} 2$ se traduit de façon très complexe au niveau de l'embryon, et on peut ainsi résumer les symptômes de carences :

- augmentation du taux lipidique des tissus parenchymateux; 
- hémorragies ;

- œdèmes ;

- nécrose du foie, des reins, du cordon spinal ;

- diminution des érythrocytes et du taux d'hémoglobine ;

- diminution de la taille et des muscles de l'embryon.

Discussion. - Nous dressons dans le tableau I la liste des organes de l'embryon de Poule atteints par les avitaminoses ainsi que les quelques anomalies provoquées par ces carences. Bien qu'un même organe puisse être touché par diverses carences, les troubles qui en résultent peuvent être caractéristiques dans certains cas : par exemple, les hémorragies survenant dans les premiers stades de développement au cours de l'avitaminose $\mathrm{E}$, et qui s'accompagnent d'un groupe de cellules profondément altérées. De même la carence folique provoque des troubles caractéristiques de l'hématopoièse.

Cependant, pour identifier une avitaminose à l'aide de l'examen des troubles engendrés chez l'embryon, il est nécessaire de procéder à des tests assez fins (histologie, par exemple) car l'examen superficiel (dissection) est incapable de résoudre ce problème. En effet, si on se reporte au tableau, on constate que 4 avitaminoses entraînent l'apparition d'œdèmes chez l'embryon ( $\mathrm{E}, \mathrm{BI}, \mathrm{B} 2, \mathrm{BI} 2)$ et que 5 carences vitaminiques diminuent 1a taille de l'embryon ( $\mathrm{E}, \mathrm{B} 2$, acide folique, biotine et BI2).

De plus, des causes variées et étrangères à la vitaminologie peuvent causer à l'embryon des dommages voisins de ceux résultant des avitaminoses.

Tout d'abord une simple cause physique exogène peut provoquer au $4^{\mathrm{e}}$ jour des troubles circulatoires mortels comme l'ariboflavinose, c'est une température d'incubation trop élevée (Alsop, 3, et RoManofF et coll., 5o). De même, une surcharge en thallium de l'embryon au $4^{e}$ jour provoque des troubles dont une partie est analogue à ceux produits par une carence folique: bec de perroquet, tête petite, yeux petits, extrémités raccourcies (KARNofSKY et coll. 37). Ces anomalies ne sont pas corrigées par les vitamines B suivantes: niacine, biotine ou riboflavine.

Des injections d'insuline entraînent également des troubles que nous avons décrits à plusieurs reprises en détaillant les répercussions des avitaminoses: syndactylisme, troubles octlaires, perosis, raccourcissement et torsion du squelette (fémur, tibiotarsus, humerus, radius et cubitus, Couch et coll., 8).

Une carence en manganèse provoque également chez l'embryon des malformations observées lors de carences vitaminiques: chondrodystrophie, œdèmes, plumage peu développé (40).

En bref, des causes multiples, nutritionnelles et même autres, provoquent chez l'embryon des lésions analogues à celles que l'on rencontre 
TABLEAU I

Lésions provoquées par les avitaminoses chez l'embryon de poule.

\begin{tabular}{|c|c|c|c|c|c|c|c|c|}
\hline \multirow{2}{*}{ Lésions: } & \multicolumn{8}{|c|}{ Carences vitaminiques: } \\
\hline & A & $\mathrm{E}$ & $\mathrm{B} \mathbf{r}$ & $\mathrm{B}_{2}$ & B6 & Ac. fol. & Biot. & $\mathrm{B}_{12}$ \\
\hline 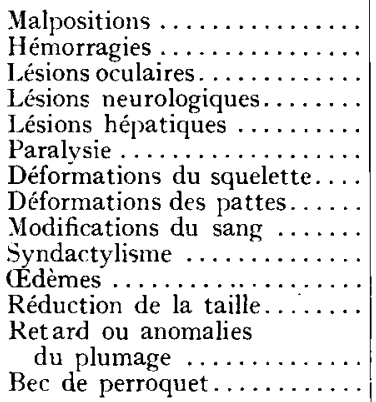 & + & + & $\begin{array}{l}+ \\
+\end{array}$ & $\begin{array}{l}+ \\
+ \\
+ \\
+\end{array}$ & & $\begin{array}{l}+ \\
+ \\
+ \\
+ \\
+ \\
+\end{array}$ & $\begin{array}{l}+ \\
+ \\
+ \\
+ \\
+ \\
+\end{array}$ & $\begin{array}{l}+ \\
+ \\
+ \\
+\end{array}$ \\
\hline
\end{tabular}

lors des avitaminoses. Ceci confirme donc le fait que les répercussions des avitaminoses ne sont pas spécifiques.

Par ailleurs, l'étude des malformations embryonnaires dues aux avitaminoses fait ressortir que celle-ci se traduit toujours d'une manière semblable. L'avitaminose BI touchera toujours le système nerveux pour aboutir à la paralysie, 1'avitaminose B2 provoquera constamment une déformation des tarses et métatarses (" curled toe "). Une déficience en acide folique entraînera une diminution de l'hémoglobine comme une carence BI2 se traduira par des infiltrations graisseuses ou un dépôt plus abondant de lipides.

C'est un résultat qui n'est pas fait pour surprendre depuis qu'on connaît les fonctions métaboliques des vitamines. Quel que soit 1'âge d'un animal ou même l'espèce considérée, il est normal que l'absence d'une vitamine, créant les mêmes perturbations biochimiques, entraîne les mêmes répercussions anatomiques ou microscopiques.

\section{III. - LOCALISATION DES MORTALITÉS EMBRYONNAIRES AU COURS DES AVITAMnNoses DE LA POULE}

Il est admis que les risques de mortalité des embryons au cours de $l^{\prime}$ incubation se localisent autour de 3 sommets situés le $\mathrm{I}^{\mathrm{er}}$, le $6^{\mathrm{e}}$ et le I 8 e jour. C'est ce que les embryologistes appellent les phases critiques embryonnaires.

La première de celles-ci, selon JEAN-BLAIN et BARONE (35), est principalement due à de mauvaises conditions de conservation de l'œuf 
avant le début de l'incubation. On pourrait dire qu'elle est d'origine exogène.

La deuxième période critique, le $6^{\mathbf{e}}$ jour, correspond à l'installation de la respiration allantoïdienne de l'embryon. La troisième, le r 8 e jour, se superpose à l'établissement de la respiration pulmonaire.

On comprend aisément que ces modifications de la vie embryonnaire soient l'occasion de la mort de l'embryon par suite d'une impossibilité à s'adapter. Dès lors, on peut se demander si une carence vitaminique de l'embryon ne peut pas être tenue pour responsable de l'arrêt du développement au moment précis où l'embryon exige un nouvel équilibre biochimique. Autrement dit, quelle peut être la responsabilité des vitamines dans les 3 périodes critiques définies par JEAN-BLAIN et BARONE, (35) ? Telle est la question à laquelle nous tenterons de répondre.

La vitamine A. - Comme nous l'avons fait remarquer précédemment, cette vitamine a été très peu étudiée chez la volaille et si on sait qu'une carence en vitamine A fait cesser l'éclosabilité, nous n'avons pas trouvé d'études détaillées sur la mortalité embryonnaire au cours de cette avitaminose.

La vitamine D. - Insko et Lyons (32), en I936, ont observé des teneurs en calcium et en phosphore particulièrement faibles pendant la troisième semaine d'incubation, et parallèlement la mortalité de l'embryon devient très forte.

Il convient de savoir qu'à partir du I2 ${ }^{\mathrm{e}}$ jour du développement, il se crée un transfert de calcium de la coquille vers l'embryon et, ainsi celuici s'enrichit rapidement en cet élément pendant la seconde moitié de l'incubation (SACCARDI et coll. 5r). L'avitaminose D inhibe ce transfert, semble-t-il, et peut provoquer la mort de l'embryon par suite d'une carence en calcium.

La vitamine E. - Adamstone (I) en I93I, et BARnum (4) en I935, ont montré tous deux que les embryons carencés en tocophérols présentaient des taux de mortalité importants la première semaine d'incubation, et notamment le $4^{\mathrm{e}}$ jour.

La vitamine $\mathrm{E}$ semble donc nécessaire principalement avant l'établissement de la respiration allantoïdienne, mais cette avitaminose provoque également parfois la mort de l'embryon avant la deuxième période critique.

Néanmoins, en travaillant sur des embryons de dindons, dont 1'incubation se poursuit 28 jours, FERGUSON (I6) en I954, a observé une mortalité notable la dernière semaine de l'incubation, c'est-à-dire — en se rapportant au poulet - pendant la troisième période critique et jusqu'à l'éclosion.

On voit donc qu'il existerait 2 sommets de mortalité au cours de 1'avitaminose E. Nous retrouverons cette observation avec d'autres facteurs vitaminiques et nous en discuterons plus loin. 
La vitamine B1. - Nous n'avons pas recueilli d'observations directes sur la mortalité des embryons de poule au cours de la carence en thiamine. Néanmoins, un travail indirect permet d'émettre certaines hypothèses : en effet, NABER et coll. (46) en I954, ont injecté dans des œufs des antithiamines (néopyrithiamine et oxythiamine) et ont montré que les embryons étaient particulièrement sensibles si l'injection se produisait pendant les 5 premiers jours de l'incubation.

On peut en déduire que la vitamine $B I$ joue un rôle très important dans la première semaine du développement, vraisemblablement jusqu'à l'épanouissement de la respiration allantoïdienne.

A l'appui de cette hypothèse on peut citer une observation de DONHOFFER (I3) montrant que les taux de glucides totaux et de sucres libres diminuaient jusqu'au $9^{\mathbf{e}}$ ou Io $^{\mathbf{e}}$ jour de l'incubation. NeEDham, de son côté, avait noté que dans les premiers stades de la croissance, l'embryon fait appel principalement à ses réserves glucidiques. Ces opérations nécessitent évidemment un certain potentiel en thiamine.

La vitamine B2. - DAvis et coll. (I2) en r938, avaient observé la courbe de mortalité des embryons subissant une ariboflavinose et noté des taux de mortalité importants aux $3^{\mathrm{e}}$ et $\mathrm{I}^{\mathrm{e}}$ jours. Il ne faut cependant pas oublier que notre connaissance des vitamines $\mathrm{B}$ à cette époque était assez sommaire, aussi accorderons-nous plus de crédit à un travail postérieur de Romanofr et BAUERNFEIND (49) effectué en I942.

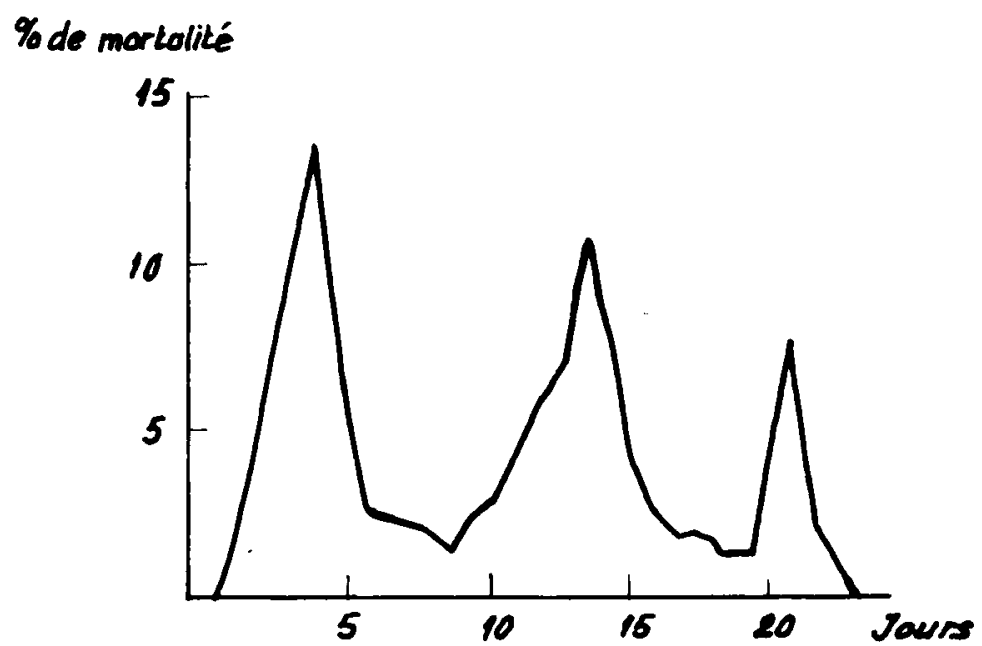

GraphIQUe I. - Courbe de mortalité embryonnaire au cours de la carence en $\mathrm{B}_{2}$ d'après Romanoff et Coll. r $9+2$.

Les résultats de ces auteurs figurent dans les graphiques I et II. On y observe 3 sommets dans la courbe de mortalité : les $4^{\mathrm{e}}, \mathrm{I}^{\mathrm{e}}$ et $2 \mathrm{I}^{\mathrm{e}}$ jours. Ein faisant varier le degré de gravité de la carence, Romanoff met en 
évidence que pendant l'incubation il se manifeste à 3 reprises un besoin vitaminique impérieux, exigeant des doses croissantes de riboflavine.

Si l'œuf ne renferme qu'une quantité infime de vitamine $\mathrm{B} 2$ - c'està-dire si la carence est très sévère - l'embryon n'a que peu de chances de survivre après le $4^{\mathrm{e}}$ jour d'incubation. Si néanmoins ce stade est franchi la croissance se poursuit sans danger jusqu'au $\mathrm{I}^{\mathrm{e}}$ jour. A ce moment-là les probabilités de mortalité augmentent subitement, et le développement exige brusquement une dose plus importante de riboflavine. Mais, bien que l'embryon ait suffisamment de vitamine pour assurer sa survie après le $4^{\mathrm{e}}$ et le $\mathrm{I}_{4}^{\mathrm{e}}$ jour, il n'est pas encore assuré de mener à bien son développement, car le $2 \mathrm{I}^{\mathrm{e}}$ jour un nouveau risque de mortalité survient.

\section{\% de mortolité}

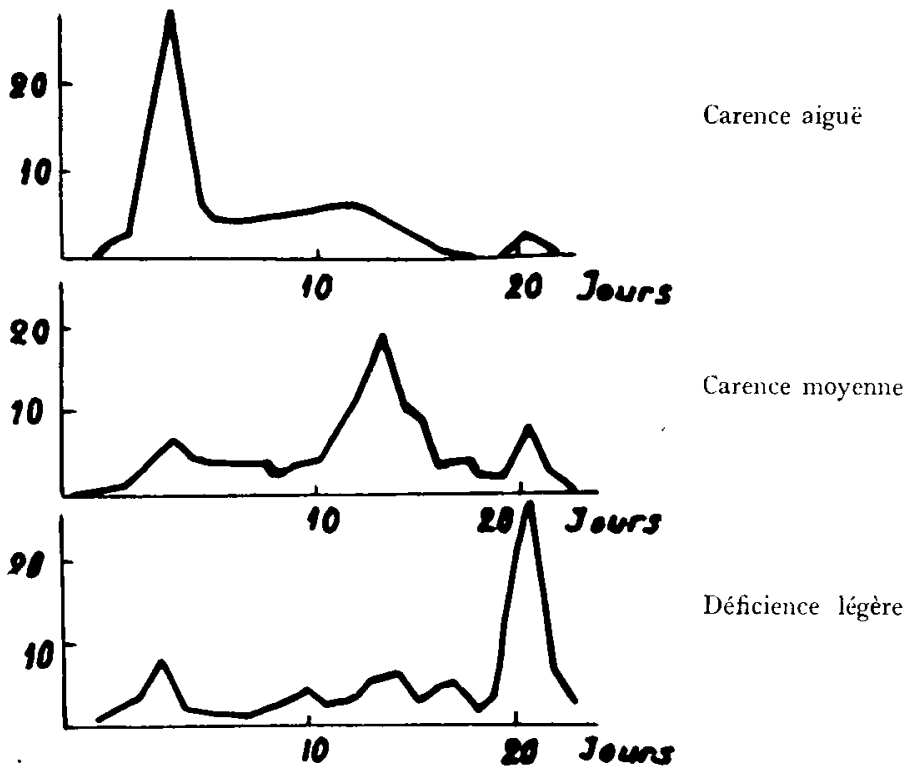

Graphique II. - Courbe de mortalité embryonnaire en fonction de l'intensité de la carence en $\mathbf{B}_{2}$ d'après Romanoff et coll. 1942.

En bref, la durée de vie de l'embryon est proportionnelle à la masse de riboflavine contenue dans l'œuf. Il faut néanmoins souligner que l'évolution de l'embryon semble se poursuivre par pallier, d'une manière discontinue.

La vitamine PP. - - Le rôle de la niacine dans la mortalité embryonnaire est difficilement mesurable, car on ne peut pas en faire varier le taux dans l'œuf: d'une part la poule synthétise la vitamine PP et ne peut être carencée en ce facteur, et, de plus, il ne passe dans l'ouf que des traces de ce facteur: il est donc mal aisé de réduire cette teneur. 
Par ailleurs, nous avons montré qu'il n'était pas possible d'obtenir des œufs enrichis en niacine par suite de surcharge de la poule. Les seuls moyens d'investigation dont on dispose sont donc les injections de vitamine ou d'anti-niacine, et aucune étude systématique n'a encore été entreprise dans ce sens. Néanmoins, il faut noter que si la niacine est pratiquement absente de l'œuf au moment de la ponte, elle se synthétise abondamment dans la deuxième moitié de l'incubation, et son taux atteint pratiquement un pallier à partir du $\mathrm{I} 8^{\mathrm{e}}$ jour.

On pourrait émettre l'hypothèse que si cette vitamine n'a certainement pas de rôle à jouer dans les premières phases du développement, l'embryon exige peut-être sa présence dans les derniers stades de sa croissance, et notamment à partir du moment où il vit en respiration pulmonaire.

La vitamine B6. - Nous n'avons pas de preuves directes du rôle protecteur de la pyridoxine vis-à-vis de l'embryon de poule.

Cependant, deux travaux relatent les conséquences de l'injection dans l'œuf de substances à activité antivitaminique.

Cravens et Snel, (II), puis Karnofsky et coll. (38) arrivent aux conclusions que la vitamine B6 doit jouer un rôle important dans le début du développement embryonnaire. A l'appui de cette affirmation, on peut rapporter l'effet de la désoxypyridoxine sur l'éclosabilité de l'œuf.

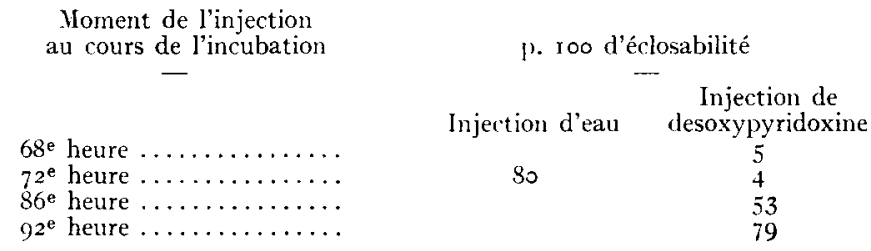

Cravens et SNELI, en concluent qu'une forte mortalité se manifeste entre le $2^{\mathrm{e}}$ et le $4^{\mathrm{e}}$ jour de l'incubation, c'est-à-dire bien avant la seconde phase critique.

KARnOFsky de son côté, a observé que la dose léthale de 50 p. Ioo est atteinte avec $0,04 \mathrm{mg}$ de méthoxypyridoxine si 1'injection est faite le $\mathrm{I}^{\mathrm{er}}$ jour de l'incubation, mais qu'il faut $3,5 \mathrm{mg}$ le $\mathrm{I} 3^{\mathrm{e}}$ jour pour obtenir le même résultat. La sensibilité des embryons est Ioo fois moindre dans la seconde moitié de l'incubation.

En résumé, l'absence, ou plus exactement 1'indisponibilité de la vitamine $\mathrm{B} 6$ a des répercussions désastreuses au début de la croissance, et CRAVENs attribue ce fait à la place que tient la pyridoxine dans le métabolisme azoté, particulièrement intense dans cette phase de l'incubation.

L'acide folique. - SUNDE et coll. (52) en I950 notent une forte mortalité embryonnaire le $20^{e}$ jour de l'incubation chez les embryons carencés en acide folique; la respiration pulmonaire est déjà établie (graphique III). Il est intéressant de noter que pour obtenir un taux d'éclo- 


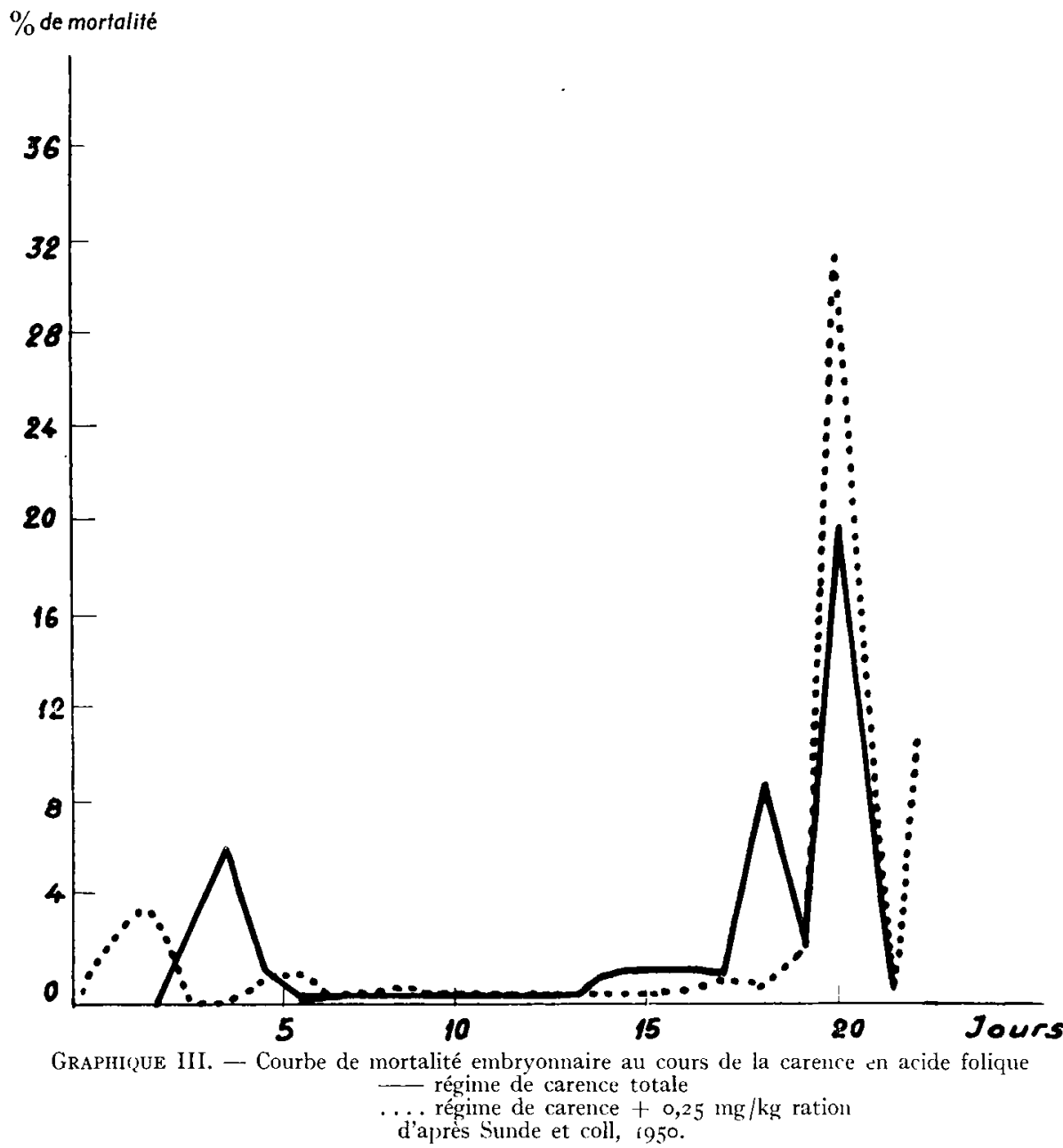

sabilité acceptable, il suffit de pratiquer une injection de vitamine le $\mathrm{I}^{\mathrm{e}}$ jour. Autrement dit l'embryon ne manifeste un besoin particulièrement important que dans les tout derniers stades de sa croissance. Cependant, les choses pourraient être un peu plus compliquées en réalité : on sait, en effet, que les carences en acide folique et en d'autres facteurs récemment découverts $(\mathrm{BI} 2)$ sont relativement difficiles à obtenir; aussi est-il possible que dans de telles déficiences l'œuf renferme encore une quantité non négligeable de vitamine suffisante pour assurer les besoins du début du développement et que seules les exigences liées aux derniers stades de croissance ne soient pas couvertes.

L'examen du graphique III confirme, du reste, ces vues, en ce sens qu'il existe une faible pointe de mortalité au $4^{\mathrm{e}}$ jour et aussi une autre vers le $\mathrm{r} 8^{\mathrm{e}}$ jour, lorsque le régime de la poule est totalement ca- 
rencée. $\mathrm{Si}$, par contre, la ration n'est pas aussi sévèrement déficiente, la mortalité est plus forte à la fin de l'incubation ; c'est-à-dire que la survie est d'autant plus longue que 1'œuf est moins déficient en acide folique. C'est ce que nous avions déjà constaté pour d'autres facteurs.

WAGLEY et MORGAN (54) arrivent à la même conclusion par une voie opposée : plus la dose d'antivitamine est forte, plus la mortalité de l'embryon est précoce. C'est ainsi qu'une dose d'un milligramme provoque la mort vers le ro jour, tandis que o,or $\mathrm{mg}$ ne provoque la mort qu'après le $\mathrm{I} 4^{\mathrm{e}}$ jour.

La biotine. - Cravens et coll. (ro) en I944, ont observé 2 périodes de mortalité chez les embryons déficients en biotine : l'une entre le $3^{\mathrm{e}}$ et

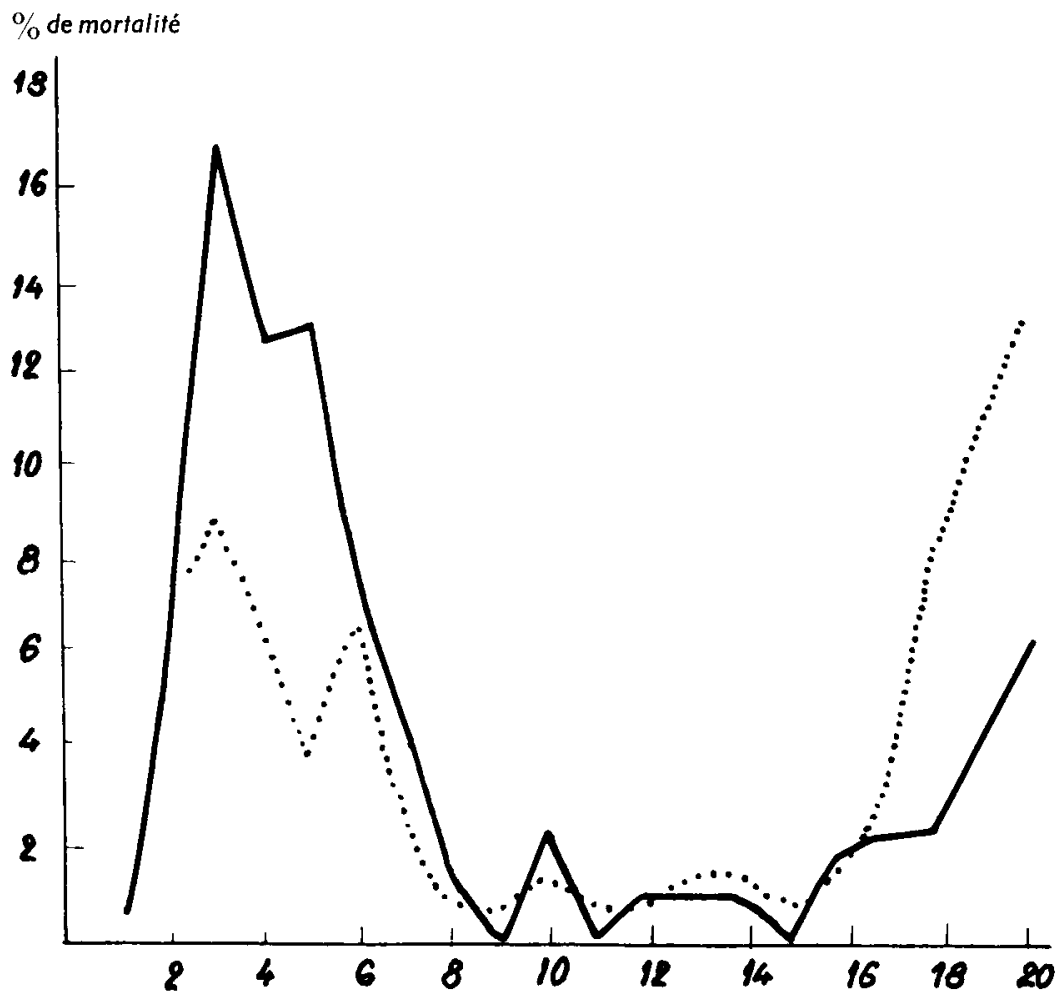

GRAPhiQue IV. - Courbe de mortalité embryonnaire au cours de la carence en biotine - - régime de carence totale $\ldots$ régime de carence $+30 \mu_{3} / \mathrm{kgr}$ ration d'après Cravens et coll, 1944 .

le $6^{\mathrm{e}}$ jour, l'autre s'étendant entre le $\mathrm{I}^{\mathrm{e}}$ et le $2 \mathrm{x}^{\mathrm{e}}$ jour de $1^{\prime}$ incubation. La même équipe (7) en 1948 , a repris cette étude et a précisé que la première pointe de mortalité se produisait principalement entre $1 \mathrm{a} 72^{\mathrm{e}}$ et la $96^{\mathrm{e}}$ heure de l'incubation, c'est-à-dire le $4^{\mathrm{e}}$ jour.

I a carence en biotine produit donc des effets comparables à ceux 
d'une ariboflavinose ou d'une carence en tocophérol : une forte mortalité dans les premiers stades de l'incubation, avant la deuxième phase critique, et une autre période de mortalité à partir de la troisième période critique et pendant la phase de respiration pulmonaire du poussin.

Mais, en plus, le graphique IV compare les effets d'une carence totale en biotine avec ceux d'une déficience moins sévère (régime de carence additionné de $30 \mu g$ de biotine par $\mathrm{kg}$ de ration). Les résultats sont très voisins de ceux observés avec des carences en $\mathrm{B} 2$ de gravité variable: si l'œuf ne renferme que très peu de biotine, la mort survient surtout au début de l'incubation, si l'œuf contient des quantités un peu plus importantes le développement se poursuivra plus longtemps; mais ce n'est qu'un répit, car si les embryons ne meurent pas au début, la mortalité survient à la fin de l'incubation.

La vitamine B12. - D'après OLCESSE et coll. (47), en I950, un sommet très net de mortalité s'observe $1 \mathrm{e} \mathrm{I} 7^{\mathrm{e}}$ jour d'incubation (graphique V). FErguson (I8), de son côté, note que le taux de mortalité le plus élevé se rencontre vers le $I 7^{\mathrm{e}}$ jour.

Les 2 observations coïncident donc exactement; la carence en vitamine $\mathrm{BI} 2$ provoque une mortalité juste avant la $3^{\mathrm{e}}$ période critique. A ce point de vue, cette carence se distingue nettement des autres déficiences vitaminiques. Seule 1'ariboflavine peut entraîner éventuellement une mortalité à cette époque de l'incubation.

Discussion. - Nous résumons dans le tableau II les périodes de forte mortalité embryonnaire dues aux avitaminoses.

On peut être frappé tout d'abord en constatant que ces pointes de mortalité ne se superposent pas exactement avec les "périodes critiques" classiquement définies par les embryologistes $\left(\mathrm{I}^{\mathrm{er}}, 6^{\mathrm{e}}, \mathrm{I} 8^{\mathrm{e}}\right.$ jours de $1^{\prime}$ incubation).

Il est donc permis de conclure que les origines de ces périodes critiques peuvent être autres que vitaminiques ou du moins que les origines en sont multiples.

D'autre part, les carences vitaminiques créent les zones de mortalité qui sont étroites (voir les graphiques et le tableau II) souvent étalées sur I seul jour ou, au plus, portant sur 2 ou 3 jours.

On constate également qu'une même vitamine peut provoquer à plusieurs reprises des zones de mortalité au cours du développement embryonnaire ; c'est le cas de la vitamine $\mathrm{F}, \mathrm{B} 2$, de la biotine et probablement de l'acide folique. La mortalité sera d'autant plus tardive, que la carence sera moins sévère.

De plus, les diverses carences vitaminiques semblent provoquer des zones de mortalité aux mêmes moments du développement embryonnaire : une première zone apparaît le $4^{\mathrm{e}}$ jour de l'incubation, une autre $s^{\prime}$ étale entre le $\mathrm{r} 8^{\mathrm{e}}$ et le $2 \mathrm{I}^{\mathrm{e}}$ jour. 
Comment expliquer ces phases de mortalité survenant au début ( $4^{\mathrm{e}}$ jour) ou à la fin ( $\mathrm{I} 8^{\mathrm{e}}$ au $2 \mathrm{r}^{\mathrm{e}}$ jour) de $1^{\prime}$ incubation. Quelle est la situation de l'embryon à ces 2 phases de sa croissance? Au $4^{\mathrm{e}}$ jour, règne une intense activité métabolique chez le futur poussin : il développe son métabolisme azoté, puise son énergie de ses réserves glucidiques, et tous ces

\section{\% de mortalité}

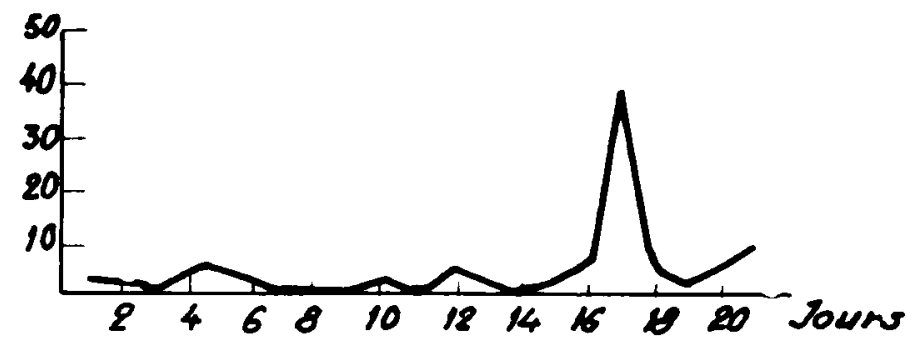

Graphique V. - Courbe de mortalité embryonnaire au cours de la carence $B_{12}$ d'après Olcesse et coll, $195^{\circ}$.

TABLEAU II

Périodes de mortalité embryonnaire dues aux avitaminoses.

\begin{tabular}{|c|c|c|c|c|c|c|c|c|c|c|}
\hline \multirow{2}{*}{\multicolumn{2}{|c|}{ Jour d'incubation }} & \multicolumn{9}{|c|}{ Carences vitaminiques } \\
\hline & & $\mathrm{D}$ & $\mathrm{E}$ & $\mathrm{Br}$ & $\mathrm{B}_{2}$ & $\mathrm{PP}$ & B6 & ac. fol & biotine & $\mathrm{Br} 2$ \\
\hline $\begin{array}{l}{ }^{\text {er }} \text { phase critique } \\
2^{\text {eme }} \text { phase critique } \\
\text { Respiration } \\
\text { allantoidienne }\end{array}$ & $\begin{array}{r}1 \\
2 \\
3 \\
4 \\
5 \\
6 \\
7 \\
8 \\
9 \\
10 \\
11 \\
12 \\
13 \\
14 \\
15 \\
16 \\
17\end{array}$ & $\begin{array}{l}+ \\
+ \\
+\end{array}$ & + & $\begin{array}{l}+ \\
+ \\
+ \\
+ \\
+\end{array}$ & + & $\begin{array}{l}+\vdots \\
+\vdots \\
+\vdots\end{array}$ & $\begin{array}{l}+ \\
+ \\
+\end{array}$ & + & + & $\begin{array}{l}+ \\
+ \\
+\end{array}$ \\
\hline $\begin{array}{c}3^{\text {eme }} \text { phase critique } \\
\text { Respiration } \\
\text { pulmonaire }\end{array}$ & \begin{tabular}{l|}
18 \\
19 \\
20 \\
21
\end{tabular} & $\begin{array}{l}+ \\
+ \\
+ \\
+\end{array}$ & $\begin{array}{l}+ \\
+ \\
+ \\
+\end{array}$ & & + & $\begin{array}{l}+? \\
+ \\
+? \\
+?\end{array}$ & & $\begin{array}{l}+? \\
+\end{array}$ & $\begin{array}{l}+ \\
+ \\
+ \\
+\end{array}$ & \\
\hline
\end{tabular}

phénomènes exigent la participation de systèmes enzymatiques dans lesquels entrent la plupart des facteurs vitaminiques, BI et B6 notamment.

On comprend dès lors qu'une carence sévère puisse empêcher l'établissement d'un de ces équilibres biochimiques et entraîne l'arrêt du développement embryonnaire.

Aux approches de l'éclosion l'embryon doit être en pleine vitalité 
et en parfaites conditions morphologiques pour donner un poussin viable. Toute déficience organique ou toute malformation physique s'opposent à ce résultat.

Dès lors, la fin de l'incubation, déjà critique en elle-même, peut aisément devenir mortelle par suite de malpositions (avitaminose $\mathrm{A}$ ), de faiblesse du squelette (avitaminose $\mathrm{D}$ ), d'anémie (avitaminoses folique ou $\mathrm{BI} 2$ ) ou d'une manière générale par suite d'un manque de vitalité des embryons carencés.

Ces observations conduisent à une analyse plus fine du rôle des vitamines dans l'œuf. Au début de l'incubation ce rôle est essentiellement métabolique. En cas de carence aiguë les réactions métaboliques intermédiaires sont bloquées et la mort s'ensuivra automatiquement. Si, par contre, la carence est moins grave, le développement embryonnaire se poursuit mais de façon anormale ; l'embryon se maintient en vie jusqu'au moment de l'éclosion, qui ne pourra se faire en raison des anomalies physiques dont souffre le futur poussin.

A ce stade, les carences vitaminiques agissent secondairement, et leurs manifestations, de biochimiques qu'elles étaient, sont devenues d'ordre morphologique et par là même mécanique.

En résumé, l'avitaminose maternelle a de graves répercussions sur le développement embryonnaire ; elle peut conduire à des taux de mortalité très élevés dont les moments se situent précocement ou tardivement selon l'intensité de la carence.

Cependant les 2 phases de mortalité des $4^{\mathrm{e}}$ et $\mathrm{I} 8^{\mathrm{e}}$ jours ont des origines qui nous semblent très différentes : la Ire correspond à des désordres métaboliques, la seconde est la conséquence d'anomalies anatomiques.

\section{RÉFÉRENCES BIBLIOGRAPHIQUES}

Revues d'ensemble:

GrRoud (A.). - Biol. revs., 29, 220-50, 1954.

Giroud (A.), LEFEBVRES (J.). - Ann. Nutrit. Alim., 11, I5-49, 1957.

JacQuot (R.). - Ann. Nutrit. Alim., 7, 39-65, I953.

WARKANY (J.). - Vit. and Horm., 3, 73-103, I945.

Articles originaux:

(I) ADAMSTONE (F. B.). - J. morphol., 52, 47-66, I93I.

(2) AdAMSTONE (F. B.). - Arch. pathol., 31, 622-6, I94I.

(3) Alsop (F. M.). - Anat. rec., 15, 307-3I, I9I9.

(4) Barnum (G. L.). - J. Nutrit., 9, 62I-35, 1935.

(5) Bologna (U.), Piccioni (V.). - Bull. soc. Ital. biol. sper., 26, 2I9-2I, r950.

(6) Chapman (M. P.). - Vet.Med., 33, I73-5, r938.

(7) Couch (J. R.), Cravens (W. W.), Ellvehjem (C. A.), Halpin (J. G.). Poultry Sci., 27, 657-6I, I948.

(8) Couch (J. R.), Cravens (W. W.), Elvehjem (C. A.), Halpin (J. G.). Poultry Sci., 28, 276-82, I949. 
(9) Couch (J. R.), Cravens (W. W.), Ellvhjem (C. A.), Halpin (J. G.). Endocrinology, 100, 29-48, 1948.

(10) Cravens (W. W.), Mc Gibbon (W. H.), Sebesta (E. E.). - Anat. Rec., 90, 55-64, I 944 .

(i1) Cravens (W. W.), Sneli (E. E.). - Proc. soc. exp. biol.med., 71, 73-6, I949.

(12) Davis (H. J.), Norris (L. C.), Heuser (G. F.). - Poultry Sci., 17, 8I-6, I938.

(I3) DoNhOFFER (C.). - Biochem. J., 27, 806-I7, I933.

(I4) Engel (R. W.), Phillips (P. H.), Halpin (J. G.). - Poultry Sci., 19, I35-42, I940.

(I5) FeLI (H. B.), Meilanby (E.). - J. physiol., 119, 470-88, I953.

(I6) FERguson (T. M.), Atkinson (R. L.), Couch (J. R.). - Proc. soc. exp. biol. med., 86, 868-7I, I 954 .

(I7) Ferguson (T. M.), Couch (J. R.). - Poultry Sci., 33, I054, I954.

(I8) Ferguson (T. M.), Couch (J. R.). - Fed. Proc., 13, 456-7, I954.

(I9) Ferguson (T. M.), Couch (J. R.). - J. Nutrit., 54, 36I-70, I954.

(20) Ferguson (T. M.), Rigdon (R. H.), Couch (J. R.). - Arch. pathol, 60, 393-400, I955.

(2I) Giroud (A.), Boisseirot (J.). - Arch. franc. pédiat., 4, 3I7-27, I947.

(22) Giroud (A.), LeFebVRes (J.). - Arch. franç. pédiat., 8, I-9, I95I.

(23) Giroud (A.), Lefebvres (J.).-C.R. Assoc. Anat., Avril i953, Bordeaux.

(24) Giroud (A.), LEVy (G.), Lefebvres (J.), Dupuis (R.). - Arch. franc. pédiat., 10, I-3, 1953 .

(25) Hale (F.). - Amer. J. Ophthal., 18, I087-93, I935.

(26) Hale (F.). - Texas J. Med., 33, 228-32, I937.

(27) Hansborough (L. A.). - Growth, 11, 177-84, 1947.

(28) HART (G. H.), MILLER (R. F.). - J. agr. research, 55, 47-58, 1937.

(29) Hogan (A. G.), O'Deli (B. L.), Whithey (J. R.). - Proc. soc. exp. biol. med., '74, 293-6, I950.

(30) Hsu (J. M.), Stern (J. R.), Mc Ginnis (J.). - Arch. biochem., 38, 26I-6, I952.

(3I) HuGHES (E. H.). - J. agr. research, 49, 943-53, I934.

(32) Insko (W. M. jr), Lyons (M.). - Kentucky agr. exp. sta., Bull. no 363 , 64-8I, I936.

(33) Jacquot (R.). - Ann. Nutrit. Alim., 7, 39-56, 1953.

(34) Jacquot (R.), Adrian (J.). Ann. Nutrit. Alim., 8, 247-330, I954.

(35) Jean-Blain (M.), Barone (R.). - Ann. Nutrit. Alim., 8, I73-94, I954.

(36) Karnofsky (D. A.), Patterson (P. A.), Ridway (L. P.). - Proc. soc. exp. biol. med., $71,447-52$, I949.

(37) Karnofsky (D. A.), Ridway (L. P.), Patterson (P. A.). - Proc. soc. exp. biol. med., 73, 255-9, I950.

(38) Karnofsky (D. A.), Stock (C. C.), Ridway (L. P.), Patterson (P. A.). 一 J. biol. chem., 182, 47I-8, I950.

(39) Lefebvres (J.). - Ann. Med., 52, 226-99, I95I.

(40) Lyons (M.), Insko (W. M. jr). - Kentucky agr. exp. sta., Bull. no 37I, $6 \mathrm{I}-75, \mathrm{I} 937$.

(4I) Mariakulandai (A.), Mc Ginnis (J.). - Arch. biochem. biophys., 37, I36-9, I952.

(42) Mason (K. E.). - Amer. J. Anat., 57, 303-49, 1935.

(43) Matzko (S. N.), Ossipova (N. M.), Dergatschev (I. S.). - Problems of nutrition, Moscou, 5, 85-98, r936.

(44) Melianby (H.). - J. dental research, 20, 839-44, I94I.

(45) Moore (L. A.), Huffman (C. F.), Duncan (C. W.). - J. Nutrit., 9, 533-5I, I935.

(46) Naber (E. C.), Cravens (W. W.), Baumann (C. A.), Bird (H. R.). J. Nutrit., 54, 579-9I, I954. 
(47) Olcese (O.), Couch (J. R.), Quisenberry (J. H.), Pearson (P. B.). J. Nutrit., 41, 423-3I, I950.

(48) Polk (H. D.), Sipe (G. R.). - Poultry Sci., 19, 396-400, 1940.

(49) Romanofy (A. L.), Bauernfeind (J. C.). - Anat. Rec., 82, i I-21, r942.

(5o) Romanoff (A. L.), Smith (L. L.), Sullivan (R. A.). - Cornell Univ. agr. exp. sta. memoir, $\mathrm{n}^{\circ}$ 2I6, I-42, I938.

(5I) Saccardi (P.), Latini (P.). - Arch. sci. biol., 19, 55-6I, I933.

(52) Sunde (M. L.), Cravens (W. W.), Eilvehjem (C. A.), Halpin (J. G.). Poultry Sci., 29, 696-706, I950.

(53) Thiersch (J. B.), Philitiss (F. S.), Wheelock (B.). - Proc. soc. exp. biol. med., 74, 204, I950.

(54) Wagley (P. F.), Morgan (H. R.). - Arch. pathol., 46, 44I-50, I948.

(55) Warkany (J.). - Amer. J. diseases Children, 66, 5 II-I6, I943.

(56) Warkany (J.), Nelson (R. C.). - Anat. rec., 79, 83-IO0, I94I.

(57) Warkany (J.), Nelson (R. C.), Schraffenderger (E.). - Amer. J. diseases Children, 64, 860-6, I942.

(58) Warkany (J.), Nelson (R. C.), Schaffenderger (E.). - J. bone joint Surg., 25, 261-70, I943.

(59) Warkany (J.), SchrafFEnBerger (E.). - Arch. Ophthal., 35, I50, I946.

(6o) Wilson (J. G.), Warkany (J.). — Anat. rec., 97, 60-73, I947. 